\title{
PENGARUH KELOMPOK PA TERHADAP PERTUMBUHAN ROHANI REMAJA GEREJA KIBAID JEMAAT SUDIANG
}

\author{
Febryanti Marrung, Armin Sukri
}

\begin{abstract}
Abstrak
Kelompok PA adalah suatu tindakan kemauan seseorang untuk mempelajari Alkitab secara mendalam dengan membentuk kelompok dan dengan tujuan yang sama dan saling menopang, saling mendukung dan saling memotivasi satu dengan yang lain. Selain itu, di dalamnya juga ada kesadaran untuk melakukan yang sesuai dan yang tidak sesuai firman Allah dari apa yang telah direnungkan bersama dan ada tanggung jawab di dalam kelompok untuk diselesaikan secara bersama. Adapun metode yang digunakan dalam penulisan ini adalah metode kuantitatif dengan menggunakan populasi dan sampel. Teknik pengumpulan data dalam penulisan ini yaitu melalui angket, wawancara, kajian pustaka dan observasi. Populasi sebanyak 20 orang dan yang menjadi sampel sebanyak 13 orang. Dari hasil penelitian ini, penulis menarik kesimpulan adalah Pertama, kelompok PA berpengaruh kepada cara berdoa remaja Gereja KIBAID Sudiang yang di mana sudah mulai ada perubahan, dan dari hasil menunjukkan berada pada antara skala selalu dan skala sering. Kedua, remaja Gereja KIBAID Sudiang melakukan firman lewat kelompok PA. Ketiga, dalam kelompok PA remaja dijarkan untuk saling bekerja sama, menolong, mengasihi, memotivasi dan bertanggung jawab dalam persekutuan belajar dalam kelompok. Keempat, dalam kelompok PA remaja belajar dalam ibadah persekutuan remaja dan kelompok PA, dan telah menghasilkan perubahan seperti buah-buah Roh dan itulah yang akan di tampilkan oleh remaja hal inilah yang di namakan bersaksi.
\end{abstract}

Kata-kata Kunci: Kelompok, Penelaahan Alkitab, Remaja, Pertumbuhan Rohani, Gereja KIBAID.

\section{Latar Belakang Masalah}

Alkitab merupakan fondasi yang kuat, atau dasar yang kokoh bagi kehidupan orang yang percaya, khususnya dalam kehidupan anak remaja. Masa remaja belum memahami arti fondasi, karena masih mencari jati diri mereka sendiri dan pergaulannya. Oleh sebab itu, sebagai orang tua dan pembina remaja dalam gereja perlu untuk menanamkan nilainilai kekristenan, lewat firman Tuhan. Sehingga semakin hari anak remaja semakin mengerti arti hidup mereka. "Firman Tuhan jikalau diterima dan diizinkan untuk masuk dalam kehidupan, akan menjadi cermin untuk membentuk kepribadian seseorang kepada cara pandang Tuhan."

Artinya bahwa firman Tuhan adalah hal yang sangat utama dalam kehidupan orang percaya jika membuka hati dan menerimanya serta melakukannya. Bukan hanya sekedar baca namun harus dimengerti lalu diaplikasikan. Seperti yang dikatakan oleh Pdt. Ro, Woo

${ }^{1}$ Mark Tabb, Alkitab Apa Yang Tertulis Dalamnya? (Yogyakarta: Yayasan Gloria, 2011), 11. 
Hoo bahwa: "begitu dibaca, seharusnya mengerti, tetapi meskipun dibaca, tidak dapat dimengerti. Tidak membaca juga bermasalah, tetapi walaupun dibaca, jika tidak dimengerti, hal itu sungguh masalah yang besar."

Lewat hal itu, sebagai orang Kristen dapat semakin dibentuk dan semakin dewasa di dalam hal moral dan kerohanian. Seperti juga yang dikatakan oleh Peniel C. D. Maiaweng bahwa "proses menjadi dewasa secara rohani merupakan tantangan tersendiri bagi orang-orang Kristen. Mereka akan mengalami berbagai hal yang menguji mereka untuk membuktikan keteguhan iman dan konsistensi mereka terhadap firman Allah."3

"Pendidikan agama Kristen untuk remaja sangat penting diberikan kepada para remaja guna membekali mereka dalam menghadapi segala kejiwaan, kepribadian, sikap dan berbagai pengaruh yang datang kepada mereka serta sebagai pedoman hidup bagi remaja." Artinya bahwa remaja merupakan kelompok yang sangat sulit dihadapi, karena banyak hal yang mempengaruhi pertumbuhan mereka. Dapat dikatakan bahwa banyak penyebab yang dapat mempengaruhi dalam masa-masa remaja, dan pengaruh terbesar yaitu datangnya dari faktor ekstern. Bagaimana faktor ekstern ini sangat berpengaruh dalam pertumbuhan rohani anak remaja. Karena yang terjadi bahwa faktor ekstern ini kurang mendapatkan pengaruh yang baik buat anak remaja, fakta yang terjadi bahwa banyak anak remaja yang tidak memiliki sikap yang sopan dan sangat cenderung kepada sikap penyimpangan moral.

Artinya bahwa perlu untuk menanamkan nilai-nilai kekristenan dalam kehidupan mereka melalui firman Tuhan, untuk menuju kepada pertumbuhan rohani mereka. Dengan keadaan seperti ini penting adanya pembinaan kepada generasi anak remaja, khususnya dalam hal pertumbuhan rohani mereka, tentunya dasar yang baik buat mereka adalah dari firman Tuhan. Namun, bagaimana seorang pembina dapat membangun minat anak remaja untuk sukacita dalam membaca firman Tuhan, tentunya tujuan yang ingin dicapai oleh pembina bukan hanya sekedar baca tetapi bagaimana firman itu mereka terima dan melakukannya. Salah satu cara yang baik untuk mengetahui isi firman Tuhan yaitu dengan membuat kelompok PA.

Dalam kelompok PA ini ada beberapa metode yang akan digunakan, agar anak remaja semakin sukacita dalam belajar firman Tuhan. "Dalam Kamus Besar Bahasa Indonesia kata penelaahan adalah orang yang menelaah, orang yang mengkaji, menyelidik, pemeriksa, peneliti. $" 5$ Hal ini bahwa firman Tuhan sangat perlu untuk dikaji atau dipelajari, karena untuk mengkaji, menyelidiki bahkan mempelajari bukan hanya tugas pendeta tetapi tugas untuk semua orang yang percaya Kristus, khususnya kepada kelompok anak remaja yang senang membuat kelompok-kelompok diluar yang sangat cenderung terpengaruh kepada hal yang negatif.

Sangat mengerikan betapa banyaknya anak yang tumbuh di dalam gereja dan keluarga kristen tanpa pernah ditangkap oleh Injil Yesus. Sebagai anak-anak dan remaja, mungkin kelihatannya mereka adalah anak-anak yang percaya; tetapi ketika mereka mencapai usia perguruan tinggi dan dewasa muda, mereka meninggalkan kepercayaannya. Mereka meninggalkan gereja.

${ }^{2}$ Ro Woo Hoo, Pembacaan Alkitab Secara Menyeluruh (Yogyakarta: ANDI, 2015), 3.

${ }^{3}$ Peniel C. D. Maiaweng, Kelompok Penelaahan Alkitab (Makassar: Sekolah Tinggi Theologia Jaffray, 2013), 3.

${ }^{4}$ Dame Taruli Simamora \& Rida Gultom, Pendidikan Agama Kristen Kepada Remaja Dan Pemuda (Medan: Mitra, 2011), v.

${ }^{5}$ Kamus Besar Bahasa Indonesia, s.v. "Penelaahan."

${ }^{6}$ Jack Klumpenhower, Kenalkan Yesus Pada Mereka (Surabaya: Momentum, 2014), 4. 
Ini adalah tanggung jawab bersama, remaja adalah masa depan yang sangat kuat buat gereja, bangsa dan negara. Penanaman nilai-nilai Kristiani buat remaja selain didapatkan dari gereja, tentunya yang paling utama adalah dari rumah. Seperti yang firman Tuhan katakan dalam:

Ulangan 6:7 "haruslah engkau mengajarkannya berulang-ulang kepada anakanakmu dan membicarakannya apabila engkau duduk di rumahmu, apabila engkau sedang dalam perjalanan, apabila engkau berbaring dan apabila engkau bangun."7

Sebagai orang tua yang percaya kepada Kristus tentunya menginginkan generasinya bertumbuh, baik itu secara fisik terlebih dalam kerohanian. Remaja zaman sekarang mereka lebih senang membaca komik, dan lebih fokus kepada gadged yang berisi statusstatus dari rekan-rekannya atau dari idolanya, sehingga anak remaja terlena dengan hal itu dan dalam keaktifannya membaca Alkitab itu sangat kurang. Sehingga timbul pertanyaan bahwa apakah yang menyebabkan hal ini terjadi? apakah karena masalah kemalasan? ataukah karena masalah gadged mereka? ataukah ada masalah lain? masalah ini bukanlah masalah baru untuk ditemukan di dalam remaja, masih banyak remaja Kristen yang melalaikan untuk belajar firman Tuhan. Oleh sebab itu, sangat penting dalam pertumbuhan rohani anak remaja dimulai dari mereka sukacita dalam belajar firman Tuhan lewat kelompok PA, khususnya yang dilakukan oleh pembina remaja.

Gereja KIBAD Jemaat Sudiang merupakan gereja yang terletak di Sudiang raya, Biringkanaya. Kota Makassar. Gereja KIBAID ini merupakan salah satu gereja yang sangat berkembang baik dari segi bangunan maupun dalam jumlah anggota. Dalam persekutuan di dalam jemaat khususnya remaja sangat penting berbicara tentang pertumbuhan rohani mereka. Apakah di dunia milenial sekarang ini pertumbuhan rohani remaja dapat bertumbuh. Dalam beberapa waktu yang lalu, dari pembina remaja telah memberikan panduan untuk membaca Alkitab sebagaimana bahwa agar berpengaruh kepada pertumbuhan rohani remaja. Namun, yang terjadi bahwa tidak sesuai dengan harapan di awal pelaksanaan yang di mana mereka setia membaca tetapi semakin hari mereka semakin redup dalam membaca Alkitab. Dengan melihat masalah yang ada, tentunya untuk menjawab kebutuhan remaja khususnya dalam hal pertumbuhan rohani perlu adanya fondasi yang kuat melalui PA. Dalam melaksanakan PA dalam persekutuan remaja, kegiatan ini sangat kurang dilaksanakan oleh sebab itu sebagai pembina remaja sekaligus sebagai peneliti akan melaksanakan kegiatan PA yang di dalamnya akan dikombinasikan dengan metode-metode dari Rick Warren.

Hal ini sangat penting bagi kehidupan remaja saat ini, sehingga hal inilah yang melatar belakangi penulis untuk menulis karya ilmiah yang berjudul: PENGARUH KELOMPOK PA TERHADAP PERTUMBUHAN ROHANI REMAJA GEREJA KIBAID JEMAAT SUDIANG.

\section{Pokok Masalah}

Sesuai dengan penjelasan latar belakang di atas, maka yang menjadi pokok masalah adalah sejauh mana pengaruh kelompok PA terhadap pertumbuhan rohani remaja Gereja KIBAID Jemaat Sudiang?

${ }^{7}$ Ulangan 6: 7 (TB). 


\section{Tujuan Penelitian}

Adapun tujuan penulisan yang hendak dicapai oleh penulis yaitu untuk melihat atau mengetahui sejauh mana pengaruh kelompok PA terhadap pertumbuhan rohani remaja Gereja KIBAID Jemaat Sudiang.

\section{Manfaat Penelitian}

Adapun manfaat dari penulisan karya ilmiah ini adalah sebagai berikut:

Pertama, mendorong remaja Kristen untuk tertarik dalam membaca dan memahami bacaan Alkitab.

Kedua, sebagai masukan bagi penulis agar dapat dapat membantu dan mendidik remaja Kristen dalam memahami bacaan Alkitab lewat kelompok PA.

Ketiga, sebagai salah satu persyaratan untuk menyelesaikan studi strata satu (S1) di sekolah Tinggi Filsafat Jaffray Makassar.

\section{Metode Penelitian}

Adapun metode yang penulis gunakan dalam penulisan karya ilmiah ini adalah metode kuantitatif.

Pertama, pengumpulan jurnal dan buku-buku yang berkaitan dengan kelompok PA, metode Rick Warren, dan tentang pertumbuhan rohani.

Kedua, dalam penelitian ini penulis akan menggunakan kuisioner/ angket sebelum menerapkan kelompok PA yang di dalamnya menggunakan metode Rick Warren. Dan menggunakan kuisioner setelah menerapkan kelompok PA dan metode Rick Warren.

Ketiga, penulis menggunakan wawancara kepada remaja dan beberapa orang tua. Keempat, dalam penelitian ini penulis melakukan pengamatan kepada remaja.

\section{Batasan Penelitian}

Dalam penulisan karya tulis ilmiah ini hanya membahas tentang Pengaruh kelompok PA terhadap pertumbuhan rohani remaja gereja KIBAID Jemaat Sudiang.

\section{Kesimpulan}

Dari hasil penelitian dan pembahasan mengenai pengaruh kelompok PA terhadap pertumbuhan rohani remaja Gereja KIBAID Jemaat Sudiang Makassar, dapat disimpulkan bahwa:

Pertama, kelompok PA berpengaruh kepada cara berdoa remaja Gereja KIBAID Sudiang yang di mana sudah mulai ada perubahan, dan dari hasil menunjukkan berada pada antara skala selalu dan skala sering. Artinya remaja mulai ada perubahan dalam hal berdoa, hal ini juga di dapatkan dari hasil wawancara dan pengamatan penulis kepada remaja dalam halaman 49-50.

Kedua, remaja juga di ajarkan untuk bertumbuh dalam firman, karena hal ini adalah sebuah pelajaran yang selalu dibahas dalam setiap pertemuan kelompok PA, dalam setiap pertemuan ibadah untuk dibaca, direnungkan dan diselidiki, dan di lakukan secara bersama. Dapat dikatakan bertumbuh secara rohani jika remaja Gereja KIBAID Sudiang melakukan firman. Dari hasil wawancara bahwa sudah ada beberapa remaja yang 
melakukan penyelidikan Alkitab di rumah bersama dengan orang tua, dapat di lihat juga dari hasil wawancara dan pengamatan penulis kepada remaja dalam halaman 51- 52.

Ketiga, remaja juga diajarkan untuk saling bekerja sama, menolong, mengasihi, memotivasi dan bertanggung jawab dalam persekutuan. Dari hasil yang di peroleh bahwa remaja Gereja KIBAID Sudiang telah bertumbuh dalam persekutuan. Selain hasil perhitungan, penulis juga melihat dari hasil wawancara dan pengamatan kepada remaja dalam halaman 56.

Keempat, remaja yang telah belajar dalam ibadah persekutuan remaja dan kelompok PA, yang di harapkan adalah menghasilkan perubahan seperti buah-buah Roh dan itulah yang akan di tampilkan oleh remaja hal inilah yang di namakan bersaksi. karena bersaksi bukan hanya menerapkan metode yang diketahui tetapi cara juga cara hidup. Beberapa remaja Gereja KIBAID Sudiang juga sering berbagi firman dan mendoakan teman mereka yang belum percaya, selain itu beberapa remaja juga rindu untuk selalu berbgai firman Tuhan, tetapi kekurangannya ialah belum ada keberanian.

Pertumbuhan rohani yang terjadi pada remaja Gereja KIBAID Sudiang memang belum semaksimal yang di harapkan. Dengan waktu pertemuan yang sangat singkat akan sulit untuk mendapatkan hasil $100 \%$. Akan tetapi, sekalipun waktu sangat singkat, jumlah remaja dalam mengikuti kelompok PA juga kurang banyak. Tetapi dampak dari belajar dalam kelompok PA membawa perubahan sedikit demi sedikit atau perubahan yang sudah mulai ada jika di bandingkan dengan sebelumnya, penulis menjalankan angket sebelum melaksanakan PA dan hasilnya bahwa banyak dari mereka yang sangat-sangat minim dapat dikatakan hanya sekedar mengetahui tetapi mengamplikasikannya tidak ada. Tetapi dengan di adakannya kelompok PA ini sangat dapat membantu pertumbuhan rohani remaja Gereja KIBAID Jemaat Sudiang Makassar.

\section{Saran-saran}

Dari kesimpulan diatas, maka penulis memberikan beberapa saran sebagai berikut:

Pertama, remaja Gereja KIBAID Sudiang harus mengalami betul pertumbuhan rohani, bukan hanya sekedar mengetahui dan bukan hanya sekedar dipelajari tetapi harus diaplikasikannya.

Kedua, dalam ibadah remaja harus diprogramkan pembelajaran PA dalam 4 kali atau lebih dalam sebulan. Karena hal ini penting bagi pertumbuhan rohani remaja.

Ketiga, pengurus sekolah minggu khususnya kelas remaja sangat perlu ada kerja sama antara guru remaja dan orang tua dalam melihat perubahan-perubahan yang terjadi dan mengarahkan apa yang menjadi kebutuhan remaja.

Keempat, guru remaja yang mengajar dalam ibadah remaja perlu untuk mempersiapkan diri dan bahan dengan baik. Seperti membuat suasana kelas dalam kelompok PA tidak monoton tetapi berbagai cara dilakukan untuk lebih kreatif.

Kelima, guru harus lakukan pendekatan dengan remaja agar remaja lebih terbuka dan dapat menerima masukan dan remaja tidak menjadi canggung.

\section{Kepustakaan}

Alkitab. Jakarta: Lembaga Alkitab Indonesia, 2012.

Brake, Andrew. Spiritual Formation Menjadi Serupa Dengan Kristus. Bandung: Kalam Hidup, 2014.

Boehlke, Robert R. Memperlengkai Bagi Pelayanan Dan Pertumbuhan. Jakarta: BPK Gunung Mulia, 2002. 
Blackaby, Norman \& Henry. Mengalami Doa Bersama Yesus. Jakarta: Metanoia, 2008.

Caliguire, Mindi. Spiritual Transformation In Relationship. Yogyakarta: Katalis, 2019.

Christanday, Andreas. Pujian Dan Penyembahan. Yogyakarta: Gloria Graffa, 2009.

Dyck, Anni. Tantangan Dan Kebutuhan Remaja. Malang: YPPII, 1982.

Edowai, Dolince. "Pengaruh Ibadah Persekutuan Mahasiswa Papua (IPMP) Terhadap Pertumbuhan Rohani Mahasiswa Papua Di Kota Makassar." Skripsi S. PAK, Sekolah Tinggi Theologia Jaffray Makassar, 2017.

Fransisca, Delvy dan Yunus D. A. Laukapitang. "Kepemimpinan Yosia Berdasarkan Kitab 2 Tawarikh 34:1-7 dan Implikasinya bagi Pelayanan Pemuda di Gereja." Jurnal Ilmu Teologi dan Pendidikan Agama Kristen 1, no. 2 (Desember 2020): 103-122. http://dx.doi.org/10.25278/jitpk.v1i2.508.

Gunarsa, Singgih D \& Yuliana Singgih D. Gunarsa. Psikologi Praktis Anak, Remaja Dan Keluarga. Jakarta: BPK Gunung Mulia, 2008.

Guthrie, Donald. Teologi Perjanjian Baru 3. Jakarta: BPK Gunung Mulia, 1993.

Hoo, Ro Woo. Pembacaan Alkitab Secara Menyeluruh. Yogyakarta: ANDI, 2015.

Hensley, Margaret F. Konsep Diri \& Kedewasaan Rohani. Bandung: Kalam Hidup, 1997.

Hickey, Marilyn. Menjadi Orang Kristen Dewasa. Semarang: Media Injil Kerajaan, 1984.

Hartanti, Mary. Eksposisi Surat Filemon Dan Surat Yakobus. Yogyakarta: ANDI, 1994.

Kamus Besar Bahasa Indonesia. Jakarta: Balai Pustaka, 2001.

Kusch. Metode Penelaahan Alkitab Secara Praktis. Jayapura: Sekolah Alkitab Malam Gereja Kristen Injili, 2004.

Klumpenhower, Jack. Kenalkan Yesus Pada Mereka. Surabaya: Momentum, 2014.

Lahaye, Tim. Mempelajari Alkitab Secara Praktis. Bandung: Kalam Hidup, 1993.

Maiaweng, Peniel C. D. Kelompok Penelaahan Alkitab. Makassar: Sekolah Tinggi

Theologia Jaffray, 2013.

Menjadi Dewasa Secara Rohani. Tenggarong: Sekolah Tinggi Teologi Tenggarong, 2003.

Mika \& Petronella Tuhumury. "Implementasi Strategi Pembinaan Menuju Pertumbuhan

Rohani Pemuda GKII Jemaat Sidu'ung Muara Berau”. Jurnal Jaffray, Volume 11,

No. 2, (2013): 1-18. Diakses 17 Juli 2019.

https://ojs.sttjaffray.ac.id/index.php/JJV71/article/view/84

Morley, Patrick. Spiritual Disciplines. Malang: Gandum Mas, 2009.

Nawawi, Hadari \& Martini Hadari. Instrumen Penelitian Bidang Sosial. Yogyakarta: Gadjah Mada University Press, 1992.

Park, Abraham. Pemeliharaan Yang Misterius Dan Ajaib. Jakarta Selatan: Damai Sejahtera Utama, 2015.

Ronda, Daniel. Kisah-Kisah Misi Singkat Diberbagai Belahan Dunia. Makassar: Sekolah Tinggi Theologia Jaffray, 2018.

Riedel, K. Tafsiran-Tafsiran Alkitab. Jakarta: Badan Penerbitan Kristen, 1955.

Santoso, Lea \& Jimmy Kuswadi. Memulai Hidup Baru. Jakarta: Persekutuan Kristen Antar Universitas, 1985.

Serli dan Hengki Wijaya. "Metode Permainan dalam meningkatkan Pemahaman Firman

Tuhan pada Remaja GKII Okahapi Sumba Timur." Jurnal Ilmu Teologi dan

Pendidikan Agama Kristen 1, no. 1 (Juni 2020): 17-28.

http://dx.doi.org/10.25278/jitpk.v1i1.459.

Simamora, Dame, Taruli \& Rida Gultom. Pendidikan Agama Kristen Kepada Remaja Dan

Pemuda. Medan: Penerbit Mitra, 2011.

Sumanto. Metodologi Penelitian Sosial Dan Pendidikan. Yogyakarta: ANDI, 1990. 
Simamora, Bilson. Analisis Multivariat Pemasaran. Jakarta: Gramedia Pustaka Utama, 2005.

Subagyo, Andreas B. Pengantar Riset Kuantitatif \& Kualitatif. Bandung: Kalam Hidup, 2004.

Sugiyono. Statistik Untuk Penelitian. Bandung: CV. Alfabeta, 2007.

Saat Teduh. Jakarta: BPK Gunung Mulia, 2009

Tabb, Mark. Alkitab Apa Yang Tertulis Dalamnya?. Yogyakarta: Gloria, 2011.

Umar, Husein. Metode Riset Bisnis: Panduan Mahasiswa Untuk Melaksanakan Riset Dilengkapi Contoh Proposal Dan Hasil Riset Bidang Manajemen Dan Akuntansi. Jakarta: Gramedia Pustaka Utama, 2002.

Warren, Rick. Metode Pemahaman Alkitab Yang Dinamis. Yogyakarta: ANDI, 2009.

Wuwungan, O. E. Ch. Bina Warga: Bunga Rampai Pembinaan Warga Gereja. Jakarta: BPK Gunung Mulia, 2004.

Wijaya, Hengki. Metode Penelitian Pendidikan Teologi. Makassar: Sekolah Tinggi Theologia Jaffray, 2016.

\section{Wawancara}

Ando. Wawancara Oleh Penulis. Makassar, 02 Agustus 2019.

Azriel. Wawancara Oleh Penulis. Makassar, 02 Agustus 2019.

Bara, Bartolomeus. Wawancara Oleh Penulis. Makassar, 21 Juli 2019.

Dea. Wawancara Oleh Penulis. Makassar, 02 Agustus 2019.

Ela. Wawancara Oleh Penulis. Makassar, 02 Agustus 2019.

Etam. Wawancara Oleh Penulis. Makassar, 02 Agustus 2019.

Ike. Wawancara Oleh Penulis. Makassar, 02 Agustus 2019.

Liku, Marni. Wawancara Oleh Penulis. Makassar, 20 Juli 2019.

Lili. Wawancara Oleh Penulis, Makassar, 02 Agustus 2019.

Maria. Wawancara Oleh Penulis. Makassar, 02 Agustus 2019.

Milka, Epi. Wawancara Oleh Penulis, Makassar, 19 Juli 2019.

Nando. Wawancara Oleh Penulis. Makassar, 02 Agustus 2019.

Nia. Wawancara Oleh Penulis. Makassar, 02 Agustus 2019.

Palengka, Suswelty. Wawancara Oleh Penulis. Makassar, 21 Juli 2019.

Rusmiati. Wawancara Oleh Penulis. Makassar 20 Juli 2019.

Tanan, Nataniel. Wawancara Oleh Penulis. Makassar, 20 Juli 2019.

Titus. Wawancara Oleh Penulis. Makassar, 02 Agustus 2019.

Yudhi. Wawancara Oleh Penulis. Makassar, 02 Agustus 2019.

Yos. Wawancara Oleh Penulis. Makassar, 02 Agustus 2019. 